UDC: 821.134.3(81).09 Eça de Queirós J. M.

DOI: https://doi.org/10.18485/beoiber.2018.2.1.8

\author{
Cristiane Navarrete Tolomei ${ }^{1}$ \\ Universidade Federal do Maranhão \\ Brasil
}

\title{
EÇA DE QUEIRÓS LIDO POR UM BRASILEIRO
}

\begin{abstract}
Resumo
O presente artigo analisa, de maneira geral, como a crítica literária brasileira sobre a vida e a obra de José Maria Eça de Queirós (1845-1900) construiu a identidade do Eça-escritor no século XX no país. Para este texto, de forma específica, apresentamos uma leitura que faz parte do cânone dos estudos queirosianos no Brasil intitulada História Literária de Eça de Queiroz (1939), de Álvaro Lins (1912-1970), verificando de que forma esse estudo foi pioneiro na época e como ele trouxe dados importantes acerca da biografia e da obra do autor português. Ademais, ressaltamos o comportamento militante de Álvaro Lins, sendo destaque na crítica literária profissional da década de 1930, e a presença da linhagem impressionaista na obra analisada.
\end{abstract}

Palavras-chave: Eça de Queirós, Álvaro Lins, Crítica Literária Brasileira, Recepção, Identidade.

\section{EÇA DE QUEIRÓS READ BY A BRAZILIAN}

\begin{abstract}
This article analyzes, in a general way, how Brazilian literary criticism of the life and work of José Maria Eça de Queirós (1845-1900) built the identity of the Eça-writer in the twentieth century in Brazil. In this paper, in a specific way, we present a reading that is part of the canon of Queirosian studies in Brazil, titled História Literária de Eça de Queiroz (1939), by Álvaro Lins (1912-1970), verifying how this study became seminal at that time and how it brought some important data about Eça's biography and work. In addition, we highlight the militant behavior of Álvaro Lins, being featured in the professional literary criticism of the 1930s, and the presence of the impressionistic lineage in the work analyzed.
\end{abstract}

Key words: Eça de Queirós, Álvaro Lins, Brazilian literary criticism, reception, identity.

${ }^{1}$ cristiane.tolomei@ufma.br 


\section{Introdução}

O presente texto analisa a crítica de Álvaro Lins (1912-1970), em sua obra História Literária de Eça de Queiroz, de 1939, na qual revela uma leitura carregada do biografismo e do impressionismo, aspectos que dominavam a crítica brasileira da primeira metade do século $X X$, e o pioneirismo no estudo sobre a vida e a obra do escritor português José Maria Eça de Queirós (1845-1900).

Ao longo do século passado, é possível observar que a crítica literária queirosiana foi sofrendo transformações no Brasil, podendo ser dividida em duas partes: a primeira, marcada inicialmente pela publicação de Eça de Queiroz, de Miguel Mello, em 1911, a qual apresenta aspectos da crítica biográfica que dominava a crítica literária brasileira na época; e nas décadas de 1930 e 1940 com críticas como as de Viana Moog, Álvaro Lins, José de Melo Jorge, Clóvis Ramalhete, entre outros, que dão continuidade às linhagens biográfica, impressionsita e psicológica, encerreando a primeira metade do século XX. A segunda parte, consiste na ruptura com o movimento que dominava a crítica literária queirosiana até 1950 , surgindo a crítica sociológica de Djacir Meneses, na década de 1960; da recepção de Paulo Cavalcanti, Heitor Lira e Arnaldo Faro, na década de 1970; da crítica acerca do jornalismo de Eça, com Elza Miné, e pela abordagem tangencialmente semiótica de Beatriz Berrini a partir dos anos 80 (Tolomei 2014). Logo, o que se tem é um movimento especular da crítica literária geral no Brasil com a crítica especializa em Eça de Queirós, já que a segunda acompanha a primeira, sendo representativa da evolução da crítica literária no país, além de ser significativa na construção da identidade literária de Eça de Queirós, sendo considerada importante no universo dos estudos queirosianos no mundo.

Mesmo a obra do autor português, recebendo uma recepção significativa da população, foram os críticos que construiram e enraizaram certas interpretações a respeito da vida e da obra de Eça que marcaram e marcam a identidade literária dele no país. De acordo com Benjamin Abdala Júnior (2000):

Eça de Queirós radicou-se no Brasil, embora aqui não colocasse seus pés, através do poder de um subcampo intelectual renovador, formado nos inícios de nossa República. A atuação dos agentes críticos desse campo abriu-lhe as páginas dos jornais brasileiros e o escritor português veio a ter mais leitores no Brasil do que em seu país de origem. Esse fato se explica pelo entrecruzamento das expectativas do escritor e seu público-leitor, entre estes e os mediadores críticos (Abdala Jr. 2000: 99).

À vista disso, o presente texto procura apresentar a leitura crítica de Álvaro Lins acerca da vida e da obra de Eça, observando como na primeira metade do século XX foi construída a identidade literária do autor português no Brasil. 


\section{2. Álvaro Lins, Eça artista}

Na década de 1930 surgiu Álvaro Lins na crítica literária brasileira, nas páginas do Correio da Manhã, do Rio de Janeiro. Considerado um crítico profissional, isto é, atuante e não circunstancial, Lins conciliou a vocação da crítica literária com outros ofícios: de jornalista, de político e de professor.

Álvaro Lins destacou-se na crítica jornalística, na qual foram concebidas as suas mais variadas análises. Além disso, em sua vasta produção como crítico nos periódicos, acrescenta-se dois livros denominados História Literária de Eça de Queiroz (1939) e A Técnica do Romance em Marcel Proust (1951).

Dando continuidade aos passos tomados pela tríade - Sílvio Romero, José Veríssimo e Araripe Júnior - Lins exerceu a tarefa de analisar e de julgar, com seriedade, obras e escritores, visando a contribuir para a vida literária brasileira. Para ele, a interpretação da literatura deveria ser entendida como fonte criadora, pois ela "é a compreensão, é a penetração, é a análise, é a reconstituição, é a revelação, é o sentido psicológico, é o poder sugestivo, é o jogo e o debate das ideias" (Lins 1963: 376).

Para Lins, adepto do pensamento de Bérgson, a crítica é uma arte literária, uma vez que ela exige do crítico um conhecimento aguçado dos juízos de valor. E é dentro dessa perspectiva impressionista que Álvaro Lins percorreu a obra de Eça de Queirós em seu estudo.

Embora Lins faça parte da crítica que defendia o valor das sensações que o texto literário proporcionava ao leitor, ele tenta ressaltar, no "Prefácio", de História Literária de Eça de Queiroz (1939), o caráter histórico e analítico com que se debruçava sobre a obra do escritor português, como é possivel notar no trecho a seguir:

Da vida de Eça de Queirós, muito conhecida através de duas ou três excelentes biografias, este livro refere bem pouco porque visa outro fim. $O$ que ele pretende é transmitir a posição intelectual de Eça em face das gerações mais novas, daquelas que não o conheceram nem sentiram a sua influência (Lins 1939: 7).

Todavia, mesmo focalizando a obra, Lins não abandona a vida do autor. Embora o seu estudo não possa ser considerado uma biografia, pelo fato de não apresentar como ponto crucial o estudo sobre a vida do autor e sim o que Eça transmitira na sua produção, verifica-se que foi complicado para Lins separar a vida da obra e vice-versa, já que para ele, Eça tivera uma vida plenamente voltada à literatura e teria sido fora da literatura que o escritor português fizera a vida. E apesar de carregar no título História Literária, o livro de Lins traz no centro de discussão, pelo viés impressionista, como Eça fora construído na mescla do homem com o artista. A respeito disso, de acordo com Lins, "a sua [Eça] biografia é a história do conflito que o explica: conflito entre o artista e o homem. O artista que procurava ultrapassar o tempo e a época, o homem que tendia a ligar-se aos problemas do seu século [...]" (Lins 1939: 16). Assim, compreende-se que o 
crítico brasileiro entende que o romance queirosiano posicionara-se tanto como uma obra literária quanto como um documento humano e social de seu país e de sua época.

No estudo histórico-biográfico de Lins, a vida do escritor português não está disposta em ordem com datas e acontecimentos, contudo, o crítico inicia seu percurso afirmando, já de imediato, que o Eça artista sobrepôs o Eça socialista, o Eça político e o Eça homem. Em consonância com esse argumento, o próprio Lins ressalta, no conflito entre o homem e o artista, que a vitória fora da "arte contra o temperamento" (Lins 1939: 17). E pensando Eça dessa forma, ele dá continuidade à visão do escritor talentoso e sem ideias que dominava os estudos críticos daquele período, deixando de lado o posicionamento social da obra queirosiana.

$\mathrm{Na}$ análise do conflito entre o homem e o artista, Álvaro Lins observa, primeiro, o posicionamento de Eça na geração coimbrã de 1865:

A posição de Eça de Queirós em face de Portugal e do mundo participa, em grande parte, da posição coletiva dos companheiros da sua idade. Dos companheiros da chamada geração de 1865 [...]

Quando esta geração apareceu em Coimbra, a decadência de Portugal tinha se tornado um acontecimento irremediável. Não era mais uma decadência só pressentida pelos filósofos, pelos historiadores, pelos críticos. Era uma cena espetacular entrando pelos olhos mais distraídos ou mais sonhadores.

A decepção para os jovens de 1865 deve ter sido tremenda. Porque não há nada de mais triste do que a decadência: é mais triste do que a morte. [...]

Diante da decadência, nenhuma atitude de meio termo seria possível tornava-se preciso escolher entre a conformidade que era a morte, e a luta, que era a vida. É uma circunstância que explica este paradoxo de céticos, à maneira de Eça, que se dedicam todos ao combate afirmativo e quase heroico (Lins 1939: 23-24).

Álvaro Lins, nessa breve apresentação da Geração de 1865, posiciona Eça em um momento politicamente conflituoso em Portugal, fato que o crítico aponta como elemento fundador da carreira artística de Eça, isto é, nas palavras de Lins Eça vivera

uma vida alheia à ação e só vendo no mundo um instrumento de criação artística. Diz-se ação aqui no seu sentido mais comum, a dos movimentos pelas realizações imediatas e utilitárias. Porque num aspecto mais amplo também Eça amou a ação. Apenas concentrou todas as suas ambições na ação intelectual, no desejo de criar uma obra e se continuar com ela (Lins 1939: 35).

Dessa forma, o que Lins apresenta é um Eça distante das agitações politicopartidárias, ainda confuso e "em procura do seu caminho verdadeiro" (Lins 1939: 35). E nessa construção identitária tanto de Eça quanto de sua obra apartidárias, Lins destaca os procedimentos artísticos e linguísticos da produção queirosiana.

Sobre a obra queirosiana, Álvaro Lins sustenta uma posição contra qualquer tipo de divisão da obra do artista em fases ou classificações, entretanto, a obra poderia ser 
interpretada "por uma circunstância que é comum e inevitável: a idade" (Lins 1939: 48). Logo, para o crítico, se houvesse algum tipo de separação da obra queirosiana, que ela fosse feita através da idade e o que viesse fora disso atuaria "mais como excitantes" (Lins 1939: 49). Em outros termos, Lins defende a hipótese de que a obra de Eça fora construída seguindo as etapas da vida: da juventude surgiu o panfletário; da fase adulta, tem-se o irônico; e, finalmente, da fase madura, o conformista. Para Lins há uma harmonia entre a atitude literária de Eça e a vida.

$\mathrm{Na}$ opinião de Lins, a "obediência" ao Realismo fez com que Eça, em muitos momentos, como em $O$ Crime do Padre Amaro e O Primo Basílio, abdicasse do seu temperamento sentimental para aceitar os limites da escola realista, que surgira, para ele, como forma de amenizar esse sentimentalismo exagerado romântico e de favorecer o estabelecimento de um equilíbrio interior. Portanto, o Realismo de Eça é entendido pelo crítico como uma recriação do real.

É um fenômeno que todos conhecemos: costumes, paisagens, figuras humanas, que estão diante dos nossos olhos, despercebidos e até insuspeitados, adquirem, de repente, forma e movimento através da arte. É que o artista, somente ele, tem o privilégio de ver, na natureza e na humanidade, de ver e de revelar, aspectos, sentimentos, perspectivas, todo um outro mundo desconhecido para os outros homens (Lins 1939: 84).

Para Álvaro Lins, o percurso mimético empreendido por Eça na construção dos romances não tira de sua produção o fio imagético responsável pela recriação do real, ou valendo-se das próprias palavras do crítico, "toda a sua obra romanesca se formará dos três elementos essenciais: sonho, observação e intuição psicológica. A fusão do sonho com a realidade num temperamento de artista" (Lins 1939: 87). Lins parte do pressuposto de que a realidade é para todos a mesma, mas só quem tem um espírito artístico consegue recriá-la de forma ficcional. Esse era o caso de Eça.

O público, no entanto, nem sempre teria entendido sua obra. Como foi observado, Eça ficou inconformado com a pífia recepção da crítica e do público em relação ao Crime, o que para o Lins “era, antes, a perplexidade diante de uma surpresa de proporções tão imprevistas" (Lins 1939: 91). Os leitores não teriam percebido que a crítica de Eça, partindo do personagem Amaro, não era contra a Igreja, mas contra o poder de manipulação do pensamento que a religião tinha naquela época. Essa visão de Lins vem na contramão do senso comum da crítica queirosiana do período, já que, nessa altura, já era aceita e difundida a ideia de que esse romance apresentava como tese a crítica à lgreja Católica. Tanto é que Lins salienta a falta de tese no Crime, argumentando que “Eça procurou, foi muito mais a verdade da arte do que a verdade da vida e que não sacrificou a literatura a nenhuma das suas paixões ou raivas de momento" (Lins 1939: 101). Ainda conforme o crítico brasileiro: 
Tivesse Eça mostrado um padre por vocação, consciente da sua missão, debatendo-se, depois, na impossibilidade do celibato, vencido pela carne e fechado à graça de Deus, então sim o livro como tese, teria atingido o seu fim. $O$ romance, porém, é que perderia a lógica e a verdade, porque, sabe-se muito bem, para o verdadeiro padre, o celibato é uma condição normal (Lins 1939: 103).

Dando prosseguimento ao seu argumento, Lins ressalta que, ao construir um padre sem vocação, Eça não estava desonrando a figura do padre, mas "desonrou-o para salvar em si mesmo, o seu caráter de romancista" (Lins 1939: 103). Em vista disso, Álvaro Lins defende o Crime contra "julgamentos injustos ou pouco inteligentes" (Lins 1939: 104) e apresenta outra perspectiva do romance que, com "exceção de alguns detalhes, o Crime do Padre Amaro é a expressão artística de uma realidade que a história confirma. Por isso pareceu e serviu, no seu tempo, como um livro de combate. Hoje, não é mais. É uma obra de arte, com um sentido histórico" (Lins 1939: 104-105).

Em vista disso, para Lins, principalmente no diálogo entre Amaro e Ferrão, Eça conseguira transmitir o seu pensamento e sua preocupação em dominar a arte. Em consonância com isso, de acordo com Carlos Reis, "Álvaro Lins revela uma consciência muito esclarecida (e, muito atual, diga-se de passagem) de como o romance foi uma solução de gênero (literário) arduamente perseguida e mesmo aprendida" (Reis 2000: 3132) para Eça.

Álvaro Lins mantém sua perspectiva crítica ao analisar O Primo Basílio, afirmando que ali Eça se utilizara dos mesmos recursos técnicos, no entanto, mais aprimorado. Todavia, o crítico brasileiro, fazendo uma leitura comparativa entre o Crime e o Primo, defende a ideia de que o segundo romance fora a continuação do primeiro "nos princípios estéticos e morais, na linguagem, no estilo, continua até mesmo na simplicidade arrogante com que ambos revelam a sua origem: o Naturalismo francês" (Lins 1939: 108). Nesse trecho, verifica-se como Lins dá continuidade à crítica de Machado de Assis (1878) ${ }^{2}$ no julgamento de que $O$ Primo Basílio é um romance naturalista, porque segue a linha de Taine. Isso está bem posto no seguinte trecho: “O pequeno círculo humano, do qual Basílio é uma flor de patifaria, tem uma localização muito menor e, ao mesmo tempo, muito mais larga; ele se integra no ambiente incaracterístico e internacionalizado da burguesia" (Lins 1939: 109).

Dessa forma, Lins conclui que no Primo, em uma ação antirromântica (não dando poeticidade ao adultério), não existem culpados e pecadores, mas o que "determinou" o desenrolar da história fora a educação dada aos jovens daquele período e, especialmente, à sociedade, que tolerava as ações deles. Lins condena a crítica de Machado, por considerar que este "levava ao máximo a sua exigência, usando de um critério que nenhum crítico pode usar, o de imaginar, para os personagens alheios, destinos diferentes"

${ }^{2}$ Machado de Assis publicou uma crítica a respeito da obra de Eça de Queirós, no dia 16 de abril de 1878, nas páginas do periódico carioca O Cruzeiro, condenando alguns aspectos da obra queirosiana, em especial, a presença do Naturalismo.

BEOIBERÍSTICA Vol. II / Número 1 (2018) | 113-123 
(Lins 1939: 112). Ao se contrapor a Machado, considera o imprevisto como elemento crucial para o andamento da narrativa, isto é, o imprevisto da gravidez de Amélia e o imprevisto da carta de Juliana.

No Primo, conforme Lins, Eça não iria punir Luísa com a morte. Viu tal desfecho como um recurso romanesco: não teria um outro fim para Luisa, a não ser a morte. De acordo com o crítico brasileiro,

a morte de Luisa realiza-se, então, como uma necessidade da arte do romance e não como uma solução moral, como infantil castigo. Trata-se de uma lógica não só humana mas também de uma lógica, digamos, ideal ou artística (Lins 1939: 115).

Desse modo, Álvaro Lins defende o argumento de que o Primo representa um "efeito romântico pelo avesso" (Lins 1939: 117), principalmente, nas cenas entre Luisa e Juliana, que eram de extrema dramaticidade. Nesse drama e na independência dos personagens, Lins concebe, nesse romance, um Eça capaz de observar a realidade sem se sensibilizar com ela, ou melhor, ele foi "desumanizado pela arte" (Lins 1939: 118).

Álvaro Lins afirma que Os Maias retomara o estilo de Eça permeado pelo humor. O efeito cômico que o crítico brasileiro observa no romance era o seu grande destaque; contudo, ele também argumenta que era um romance que parecia um retrato incompleto do ponto de vista aristotélico. Mesmo revelando essa fragmentação, que, para Lins, era negativa, insistiu na escolha de Os Maias como o grande romance de Eça.

Notando o gosto do autor pela fantasia, explica a existência de textos como $O$ Mandarim e $A$ Relíquia, que se apoiam na realidade para mostrar "seus devaneios mais libertários" (Lins 1939: 128). Desses livros, Lins destaca $A$ Relíquia e a sua recepção na crítica que, em geral, fora positiva, com exceção daquela de Pinheiro Chagas, que, ao escolher a cena do sonho de Teodorico, condenou-a sumariamente: "a impossibilidade do sonho em face das condições pessoais do personagem" (Lins 1939: 133). Esse argumento perpassara o tempo e Lins se sentia na obrigação de revisá-lo, pois, como ele próprio afirma “já é tempo de tentar, com os novos elementos de hoje, uma revisão nesta impossibilidade não só psicológica mas literária que Pinheiro Chagas afirmou para o sonho da Relíquia" (Lins 1939: 134).

Lins não aceitava a hipótese de Pinheiro Chagas de que o personagem Teodorico fosse tratado como um "pateta" e um "devasso", o qual não teria repertório intelectual para sonhar com o episódio da Paixão de Cristo. Nesse ponto, Lins ressalta que Chagas usara um método crítico inadequado, pois ele portara-se "como um crítico realista", enquanto Eça estava "no domínio da fantasia” (Lins 1939: 139). Ou seja, Lins resume o assunto, afirmando que Pinheiro Chagas ficara estarrecido com "O controle entre 0 indivíduo que sonhou e o sonho que lhe é atribuído" (Lins 1939: 143-144), e que ele não conseguira perceber que o sonho de Teodorico fora o resultado da formação inicial do personagem, voltada aos preceitos religiosos. 
Lins destaca a força criadora dos personagens de Eça os quais superaram o tempo e atingem outras gerações. Isso se daria porque Eça construiria personagens de fácil entendimento, principalmente, pelo fato de não se aprofundar no íntimo deles. "Eça nunca perscrutou $O$ 'mistério' dos personagens como nunca se deteve em interrogações muito demoradas diante da vida" (Lins 1939: 230). A respeito dessa característica, Lins considera Eça um naturalista no sentido literário e metafísico, pois o autor centrara-se nas descrições físicas dos personagens, o que resultara em um traço "objetivo, superficial e plástico" (Lins 1939: 230). A construção dos personagens queirosianos giraria em torno de sua ação e da relação entre eles e o escritor: "O privilégio de amar e odiar personagens, de se apaixonar a favor ou contra, mas com um sentimento de artista que não tem nada que ver com os sentimentos da outra vida, da vida de todos os dias" (Lins 1939: 233 234). O crítico enfatiza que, na humanidade dos personagens, Eça apresentara uma característica predominante: a memória.

Eça evoca o passado dos seus personagens, reconstitui-o ao lado do presente, para mostrar as marcas e as fixações que os momentos vão deixando nas almas. Que vão desenvolvendo os destinos sem que, muitas vezes, as almas sintam que estão marcadas (Lins 1939: 237).

Segundo o crítico, Eça se posicionara diante da vida por meio de seus personagens, como se o autor virasse "um espectador", "alguém que olha, que tira conclusões, que ri do espetáculo, que aparece, por esnobismo ou por amizade, no meio dos atores, mas que só quer uma cadeira do lado de fora" (Lins 1939: 243). E para dar conta da transposição do real para o ficcional, Lins ressalta mais uma vez o estilo de Eça:

Dominar as palavras, para expressão das ideias ou da imaginação, no seu sentido pessoal, sem se isolar, e no sentido geral da "correspondência" com o público, sem se vulgarizar, parece que foi o grande ideal artístico de Eça de Queirós. E diante dele, como o elemento mais simples do problema artístico, colocou-se a língua que seria o seu instrumento verbal (Lins 1939: 247-248).

Em vista disso, para Eça revelar as verdades humanas seria necessária uma inovação literária, uma reforma da língua portuguesa, lutando para que as palavras fossem livres e se soltassem da "sintaxe apertada em regras invioláveis, as palavras muito sovadas pelo mesmo uso excessivo, os substantivos unidos com os adjetivos sempre da mesma maneira como casais sem filhos" (Lins 1939: 249). Para Lins, Eça sabia que o único meio de ele ser lembrado nas próximas gerações, de ser imortalizado seria por meio da linguagem, "marca da sua nobreza e da sua ascensão" (Lins 1939: 263).

Eça descreveria o mundo de uma perspectiva ampla, pois, nas palavras do crítico, "[Eça] compreendeu que não pode existir uma literature de partido, de classe, de regime; que a literatura será expressão da vida, mas nunca das suas divisões, no serviço mesquinho da direita ou da esquerda, dos grupos ou das ideologias" (Lins 1939: 299- 
300). Lins identifica uma relação harmônica entre o que é humano e o que é artístico na obra de Eça, revelando que o seu socialismo "foi muito mais um sentimento do que uma ideia" (Lins 1939: 288).

Exprimindo artisticamente a vida, Eça também exprime as contradições que ela contém. Atraiu para si mesmo, por isso, a acusação que devia cair sobre os fatos. É que ele não era um filósofo ou um doutrinário mas um artista Manteve sempre, no entanto, do seu ponto de vista pessoal, atitudes harmônicas e coerentes. O que não ficou foi imutável em algumas ideias fixas que o tornariam louco, no tumulto episódico e ideológico do século XIX (Lins 1939: 281).

A partir desse trecho, verifica-se que Álvaro Lins defende essencialmente um Eça artista, afastando-o do universo político. O crítico divide a obra de Eça, do ponto de vista político-social, em dois momentos: "na mocidade é a crítica feroz e brutal da sua pátria - a crítica do panfletário - mas sempre com o pensamento numa pátria melhor; será depois o amor expresso e declarado do artista que os anos tornaram sereno e mais compreensivo" (Lins 1939: 282). Por conseguinte, pode-se inserir Álvaro Lins no grupo de críticos queirosianos que não concebem a obra de Eça como instrumento de luta política e social. Tanto é verdade que o crítico chama a atenção dos leitores do autor português para que eles "não tomassem muito ao pé da letra" (Lins 1939: 282) as palavras dele sobre Portugal.

Assim, Lins considera que, na obra de Eça, havia mais uma revolta frente ao que parecia não poder mudar em seu país do que uma perspectiva socialista e revolucionária de transformação dessa realidade. A respeito disso, o crítico brasileiro salienta que era "preciso que um povo nem fique a vida toda olhando para trás, contemplativo e estático, nem avance tumultuariamente quebrando as suas tradições - eis o sentiment nacional de Eça de Queirós" (Lins 1939: 297).

Ao que tudo indica, Lins concebe um Eça que via na ideia de civilização a solução para os problemas de Portugal, mas não um progresso avassalador e desumano. Ademais, o crítico destaca o fato de que grande parte da crítica entendia que a obra de Eça era uma entrega ao estrangeiro, sendo que, para Lins, era exatamente o oposto.

É possível verificar, no estudo de Lins, uma leve diferença dos críticos de sua época em relação à leitura da obra do autor português: em vez de procurar a obra no homem, ele procurou o homem na obra. Contudo, manteve as perspectivas biográfica e impressionista como os demais.

Por fim, observamos que Álvaro Lins concebe a obra de Eça como um todo orgânico, em que estariam ligadas às obras iniciais àquelas escritas na fase madura, todas com um único propósito: representar artisticamente a realidade portuguesa (e por que não mundial) do final do século XIX. 


\section{Considerações Finais}

O papel da crítica é fazer falar o texto literário, visando encontrar as muitas e por vezes contraditórias verdades que emanam das palavras. Assim, foi o papel da crítica queirosiana no Brasil durante o século XX, elucidando, na hoje já clássica obra de Eça de Queirós, sentidos que um leitor comum não encontraria.

A obra de Eça de Queirós, por ser vasta e rica, é um desafio para a crítica, a qual transita por temas polêmicos desde o caráter plagiador do autor, passsando pelos debates da escola realista-naturalista dos primeiros romances e por suposições de um póssivel conformismo da última da produção literária do escritor. Ademais, percorrer a biografia de Eça, tomando-a ou não como modelo para a obra, observar um possível conflito psicológico decorrente da situação de "bastardia" do escritor, enfim, analisar criticamente as várias facetas de Eça de Queirós: O homem, O romancista, o jornalista, o revolucionário e o conformista.

As vozes dos queirosianos brasileiros revelam a herança literária que o escritor português deixou no Brasil. Os estudiosos se debruçaram sobre a vida e a obra de Eça por meio de diversos olhares - ora de admiração, ora analítico-investigativo, ora descritivo, ora desconfiado - assumindo diferentes perspectivas críticas face ao texto do escritor. Essas diversas leituras se cruzam, complementando-se, mas também entram em conflito e se tangenciam. Porém, o que elas têm em comum é a legitimação da obra de Eça no Brasil.

A crítica queirosiana brasileira consagrou a identidade literária do autor português no país e Álvaro Lins foi um dos grandes expoentes da primeira metade do século XX. Nesse momento da crítica sobre Eça de Queirós, delineava-se uma imagem do escritor mais como a de um dândi talentoso, que sabe fazer grandes provocações ao modo de vida português, mas não como um crítico militante da realidade nacional.

No estudo de Álvaro de Lins, a aproximação entre a vida e a obra possibilitou que o leitor brasileiro, da primeira metade do século XX, frequentasse a intimidade de Eça de Queirós e, ao mesmo tempo, cultivasse os aspectos artísticos da obra queirosiana. Lins, por muitas vezes em História Literária de Eça de Queiroz, apresenta um tom admirativo, mostrando ao público que Eça fazia parte do patrimônio do Brasil.

Essa imagem de Eça se afirma e se destaca na crítica de Álvaro Lins, já que concebe o escritor português como um grande artista, porém jamais como um grande crítico social. Para Álvaro Lins, Eça é imortal por seu talento artístico, perspectiva que será mudada pela crítica queirosiana brasileira da segunda metade do século XX.

\section{BIBLIOGRAFIA}

Abdala Júnior, Benjamin (Org.). Ecos do Brasil: Eça de Queirós, leituras brasileiras e portuguesas. São Paulo: SENAC, 2000. 23-37. Impresso. 
Lins, Álvaro. História Literária de Eça de Queiroz. Rio de Janeiro: José Olympio, 1939. Impresso.

—. Literatura e vida literária: diário e confissões. Rio de Janeiro: Civilização Brasileira, 1963. Impresso.

Mello, Miguel. Eça de Queirós. A obra e o homem. Rio de Janeiro: Livraria Italiana e Tipografia Ramori \& Cia., 1911. Impresso.

Reis, Carlos. "Leitores brasileiros de Eça de Queirós: algumas reflexões". Benjamin Abdala Júnior (Org.), Ecos do Brasil: Eça de Queirós, leituras brasileiras e portuguesas. São Paulo: SENAC, 2000. 23-37. Impresso.

Tolomei, Cristiane Navarrete. A recepção de Eça de Queirós no Brasil (Leituras críticas do século XX). São Paulo: Scortecci, 2014. Impresso.

Fecha de recepción: 25 de octubre de 2017. Fecha de aceptación: 28 de noviembre de 2017. 